\title{
Histórico da Criação do MuArq Museu de Arqueologia da universidade Federal de Mato Grosso do Sul
}

\author{
Gilson Rodolfo Martins*
}

A criação do Museu de Arqueologia da Universidade Federal de Mato Grosso do Sul (MuArq) é fruto de um longo período de pesquisas arqueológicas, de coletas de materiais científicos, de projetos financiados por órgãos de fomento e do esforço coletivo de professores ligados à Universidade. Em um ano de funcionamento, o MuArq já recebeu mais de 3.000 visitantes entre pesquisadores, estudantes e público em geral.

Palavras-chave: Museu. Arqueologia. História

The creation of the Museum of Archeology of the Federal University of Mato Grosso do Sul [MuArq] has been the fruit of a long period of archeological research, colection of scientific materials, projects financed by supportive institutions and the collective effort of professors linked to the University. During the first year of its functionning, the MuArq received more than 3000 visitors - presearchers, students and the public, in general.

Keywords: Museum. Archeology. History.
$\mathrm{N}$ ão pretendemos, neste texto, discutir o surgimento e a trajetória temporal do MuArq na perspectiva da História das Instituições. Devido à natureza desse tipo de abordagem, indissolúvel de um olhar sobre a história cultural de Mato Grosso do Sul, tal escopo será realizado em outra oportunidade, em um enquadramento textual que privilegie uma acareação dos fatos com os princípios da moderna museologia. Dessa forma, neste texto, menos pretensioso, discorreremos sobre o alinhamento dos principais episódios que pontuaram a dinâmica científica e cultural que culminaram na criação do MuArq.

Pode parecer estranho historiar uma instituição que está completando seu primeiro aniversário de fundação na semana do evento "I Encontro de

\footnotetext{
* Doutor em Arqueologia pela USP. Professor Titular de Arqueologia Pré-histórica no Departamento de História do Campus de Aquidauana - UFMS - gilson.martins@pq.cnpq.br
} 
Arqueologia de Mato Grosso do Sul", mais precisamente, em 19 de maio de 2009, um ano após a inauguração e abertura ao público da Exposição de Longa Duração. Poderia se considerar que um ano, apenas, ainda não é um tempo histórico. Na verdade, os acontecimentos que levaram à criação do MuArq, tiveram início quase duas décadas atrás, quando, no ano de 1990, foi criado o Laboratório de Pesquisas Arqueológicas do Departamento de História do Centro Universitário de Aquidauana (LPA), o qual, seria implantado dois anos após, em Campo Grande.

Em seguida, por meio de uma Portaria (Portaria 0279/91 - RTR), o então Reitor da UFMS, Prof. Fauze Gatass, constituiu uma comissão de professores ${ }^{1}$ com o objetivo de realizar os estudos necessários para a criação de um museu universitário que abrigasse distintas áreas do conhecimento científico e tecnológico. Essa preocupação surgiu em meio à visita realizada pelo então Governador de Mato Grosso do Sul, Pedro Pedrossian, à Reitoria da UFMS, logo após a sua posse, na gestão que teve início em janeiro de 1991. Na ocasião, pela primeira vez, foi formulada uma proposta oficial no sentido de que fosse construída no estado uma instituição museológica voltada para a preservação, conservação e divulgação científica do passado estadual, desde suas origens pré-coloniais até o momento da divisão territorial do extinto Mato Grosso e também sobre as especificidades ambientais desse espaço regional. A idéia original focava a implantação de uma unidade museológica, com um perfil multidisciplinar, próxima ao clássico modelo dos museus de história natural, que seria denominado Museu Estadual de Mato Grosso do Sul. A comissão constituída encomendou uma consultoria técnica em museologia junto ao Museu de Arqueologia e Etnologia da USP, que designou para tal a Prof ${ }^{a}$. Dra Maria Cristina de Oliveira Bruno. A referida professora apresentou uma proposta museológica denominada "Museu do Estado de Mato Grosso do Sul”. Segundo o que se pode observar no texto dessa proposta:

Concebido a partir de bases museológicas, este museu deverá atuar no sentido de promover o estudo, a preservação e a divulgação dos aspectos ambientais relevantes desta região do país, com ênfase para a fauna e flora, das diferentes formas de

\footnotetext{
${ }^{1}$ A Comissão citada foi composta pelos seguintes professores e técnicos da UFMS: professores, Gilson Rodolfo Martins (CEUA), presidente, Dulcemira Campisani Moreira da Silva (CCHS), Marco Aurélio Martins Rodrigues (CCBS), Antonio Carlos Marini (CCBS) e Luis Carlos de Freitas (CCET) e a técnica da PREAE, Maria Elisa Hindo Ditmar.
} 
assentamento humano ao longo do tempo e seus respectivos traços culturais, bem como, deverá se preocupar em assinalar as conquistas tecnológicas. Procurando atuar como um pólo de equilíbrio entre a preservação e o desenvolvimento, esta instituição deverá cumprir, também, um papel educacional no sentido de transmitir os resultados das pesquisas realizadas pela Universidade.

No entanto, as discussões realizadas e as idéias geradas por essa comissão não se materializaram em ações concretas. Como não houve um consenso entre os representantes das diferentes áreas do conhecimento sobre a direção a seguir, nem um engajamento direto e mais profundo por parte da administração universitária, a implantação da proposta museológica foi adiada e os esforços até então desenvolvidos se dispersaram. De concreto, resultou apenas que, em outubro de 1992, houve a concessão provisória e insuficiente, por parte da administração superior da UFMS, do espaço de uma extinta sala de aula de redação do Curso de Jornalismo, em Campo Grande, onde, atualmente, está sediada a Comissão Permanente de Vestibular da Pró-reitoria de Ensino de Graduação. Naquele momento, o citado local foi destinado para sediar a Coleção Zoológica de Referência do Curso de Biologia do CCBS e a Coleção Arqueológica. O material arqueológico era proveniente dos primeiros projetos de pesquisas arqueológicas desenvolvidos com o desdobramento do Programa Arqueológico de Mato Grosso do Sul, mencionados a seguir, como também dos primeiros conjuntos de vestígios arqueológicos coletados na execução dos projetos de salvamento arqueológico na área da UHE Sérgio Motta e do Gasoduto Bolívia-Brasil. Mesmo sendo um local muito reduzido, incapaz de abrigar duas atividades científicas distintas e dinâmicas como as retro-citadas, depois de alguns poucos anos, já na gestão seguinte da Reitoria da UFMS, a Coleção de Arqueologia foi desalojada do espaço onde até então se encontrava, sendo, mais uma vez, provisoriamente instalada em uma área exígua, então nas dependências de uma das unidades da Pró-reitoria de Administração.

Nessa época, a pesquisa arqueológica, em Mato Grosso do Sul, já dava sinais de que cresceria geometricamente em resposta ao potencial fenomenológico subjacente no território estadual. A prática sistemática e contínua da ciência arqueológica, no estado, teve início a partir de 1986, quando, uma aproximação institucional entre a UFMS e o Instituto Anchietano de Pesquisas/UNISINOS Universidade do Vale dos Sinos -, sob a coordenação do Prof. Dr. Pedro Ignácio Schmitz, resultou na elaboração conjunta de um programa de pesquisas arqueológicas. A proposta de trabalho científico visava, naquele momento, diagnosticar 
panoramicamente o perfil do passado arqueológico estadual por meio da execução de trabalhos de levantamento arqueológico em áreas amostrais representativas das características geográficas e ambientais do quadro natural sul-matogrossense. Foram desenhadas arbitrariamente quatro áreas retangulares, com vinte mil quilômetros quadrados cada, localizadas próximo às cidades de Corumbá, Três Lagoas, Dourados e Porto Murtinho. O desenvolvimento dos trabalhos de campo realizou-se, concomitantemente, em duas frentes: a equipe da UNISINOS, acompanhada de pesquisadores do Campus de Três Lagoas/UFMS, sob a coordenação do Prof. José Luis Lorenz, realizou os estudos preliminares de levantamento na região do Bolsão (nordeste do estado) e a equipe do CEUD/UFMS, coordenada pelo, Prof. Gilson Rodolfo Martins, o fez na região central e sudoeste, sobretudo em Maracaju e na área de outros municípios presentes no planalto MaracajuCampo Grande. Em seguida, na passagem da década de oitenta para a de noventa do século passado, a equipe da UNISINOS associou-se a pesquisadores do CEUC/UFMS, dando início aos estudos arqueológicos no Pantanal de Corumbá, enquanto que os pesquisadores sob a coordenação do autor deste histórico ampliaram a sua atuação para a região do município de Aquidauana, ocasião em que foram feitas as primeiras prospecções arqueológicas no sítio de Santiago de Xerez e o registro de expressivos sítios arqueológicos com arte rupestre, entre eles aquele conhecido como Sítio do CERA, e o Sítio do Morro dos Desenhos.

No ano de 1991 foi assinado um convênio, por prazo indeterminado, entre a UFMS e o Museu de Arqueologia e Etnologia da USP, com vistas à manutenção de um intercâmbio científico na área de Arqueologia. Nesse mesmo ano, a UFMS recebeu a visita oficial dos Profs. Denis Vialou e Águeda Vilhena-Vialou, respectivamente Vice-diretor do Museu do Homem, unidade do Museu Nacional de História Natural da França (MNHN), sediado em Paris e pesquisadora do Instituto de Paleontologia Humana, do CNRS/França. A partir de então, o LPA passou a colaborar com a Missão Franco-brasileira, equipe científica binacional (USP e MNHN) que desenvolvia, como o faz até hoje, pesquisas arqueológicas em Rondonópolis, sul de Mato Grosso, abordando um horizonte arqueológico comum ao norte de Mato Grosso do Sul.

As comemorações dos "500 anos de descobrimento da América" coincidiram com as celebrações do primeiro centenário da fundação de Aquidauana, em 1992. Em vista da relevância dessas efemérides, nesse ano, foi realizada, pelo 
LPA, sob nossa coordenação, a primeira exposição científica sobre a Arqueologia de Mato Grosso do Sul, a qual foi denominada "Aquidauana, 1000 anos de Arte e Arqueologia", simbolicamente representando a primeira iniciativa concreta de divulgação do conhecimento e do potencial arqueológico de Mato Grosso do Sul.

Ainda em 1992, com o avanço das obras para a construção da Usina Hidrelétrica (UHE) Sérgio Motta (Porto Primavera) a CESP - Companhia Energética de São Paulo, em atendimento à legislação em vigor, a partir da mediação efetuada pelo Prof. Dr. José Luiz de Morais, integrante do MAE/USP, firmou um convênio com a UFMS para a execução dos estudos de arqueologia preventiva na margem direita do rio Paraná, na área dos municípios impactados pela construção do reservatório desta UHE. Em vista disso, em dezembro do mesmo ano, o IPHAN endereçou à UFMS um ofício (Of. n. 47 de 3.12.92) solicitando que a UFMS criasse uma unidade específica para a área de Arqueologia e atividades afins, visando credenciá-la para receber e realizar a guarda legal e a curadoria do acervo proveniente das pesquisas arqueológicas de salvamento na área impactada pelo reservatório retro-citado. A intervenção do IPHAN no processo fez com que, em 16 de agosto de 1993, o Reitor da UFMS, emitisse uma Portaria (n. 690) implantando a Seção de Apoio à Arqueologia e Etnologia da UFMS, vinculada ao Gabinete da Pró-reitoria de Pesquisa e Pós-graduação. Pelo texto de tal Portaria, a caracterização do órgão assim ficou definida:

órgão responsável pela prestação de apoio, estímulo, cooperação e intercâmbio de estudos, pesquisas, trabalhos e experiências nas áreas de Arqueologia e Etnologia.

As competências previstas foram as seguintes:

- prestar apoio na elaboração de inventários, na classificação, na conservação, na proteção, na restauração e na revitalização de bens de valor cultural e material existentes na UFMS;

- compreender e estimular atividades de extensão voltadas às áreas de arqueologia e etnologia;

- preservar, expor e publicar informações sobre objetos de valor arqueológicos;

- executar e controlar os serviços de apoio administrativo necessários ao desenvolvimento das atividades sob sua responsabilidade;

- colaborar na preparação de documentos da documentação necessária para o credenciamento da UFMS junto aos agentes financiadores de pesquisas das áreas de Arqueologia e Etnologia; 
- providenciar a documentação necessária para o credenciamento dos profissionais de arqueologia;

- indicar um arqueólogo como gestor e responsável por projeto a ser desenvolvido;

- colaborar na elaboração dos relatórios técnicos referentes aos sítios arqueológicos;

- manter cadastro de pesquisas realizadas nos sítios arqueológicos, bem como seus relatórios para intercâmbio de experiências com outras instituições;

- desencadear outras atividades dentro de sua área de atuação.

No entanto, as questões técnicas de guarda e curadoria do material arqueológico proveniente das pesquisas em andamento continuaram mal solucionadas. Apesar da nomeação de um servidor da UFMS - sem nenhum tipo de formação nessa área científica - para ocupar a chefia dessa seção, ela não saiu do papel. Não foi constituído um espaço apropriado para tal, nem tampouco houve dotação orçamentária, nem qualquer outra medida que, de fato, significasse a constituição de uma infra-estrutura mínima para a realização das tarefas que seriam de sua competência. Enfim, não houve nenhum tipo de envolvimento ou comprometimento concreto por parte da administração universitária daquela Pró-reitoria naquele momento. Poucos anos após, na administração seguinte, a Seção foi extinta. Embora a atuação dessa Seção tenha sido praticamente nula, isto no sentido de alavancar as pesquisas e mesmo de garantir a salvaguarda do acervo arqueológico coletado durante o desenvolvimento dos projetos em vigor naquela época, pode-se considerar esse ato administrativo como um precedente que abriu espaço institucional para que, anos mais tarde, a necessidade crescente e progressiva de criação de um museu específico para guarda do acervo arqueológico estadual fosse atendida.

Por ocasião da construção do trecho do Gasoduto Bolívia-Brasil, em Mato Grosso do Sul, a PETROBRÁS, em obediência à legislação em vigor, contratou a equipe do LPA para executar os trabalhos técnico-científicos de mitigação dos impactos sobre o Patrimônio Arqueológico no trecho entre Terenos e Três Lagoas. Os trabalhos arqueológicos anteriormente mencionados tiveram início em 1993 e apresentaram, ao final da obra, em 1999, relevantes resultados científicos, os quais constituíram um acervo de milhares de peças arqueológicas (evidências materiais de diferentes horizontes culturais pré-coloniais e pré-históricos), como também um significativo banco de dados composto por fotografias dos locais 
impactados, dos processos construtivos do empreendimento, das escavações arqueológicas, de imagens aéreas e material cartográfico.

A guarda e curadoria permanente do material arqueológico coletado, atividade técnica complexa e onerosa, foi feita com a participação única do LPA, o qual foi, até então, o organismo responsável pelos custos operacionais e físicos da ação técnico-científica, a qual pode ser caracterizada como uma modalidade de ciência aplicada.

Como a infra-estrutura provisória do LPA não atendia as exigências legais para o cumprimento das determinações técnicas de guarda e curadoria, graças à intervenção do Vice Reitor da UFMS, naquele momento, o Prof. Amaury de Souza, no ano de 1998, as instalações laboratoriais do LPA foram transferidas para o local que, até, então, havia sido ocupado pelo Departamento de Educação Física, no subsolo do Estádio “Morenão". Porém, também aí a permanência do LPA assumiu um caráter provisório.

Embora as exigências acima estivessem sendo atendidas de forma minimamente satisfatória, a divulgação periódica e a multiplicação dos resultados científicos alcançados, fatores decisivos para a socialização do conhecimento e a formação de uma consciência preservacionista junto à população, não estavam devidamente contemplados devido às limitações físicas e financeiras do LPA. Em outras palavras, ações educativas em prol da tolerância multicultural e pluriétnica, capazes de viabilizar, inclusive, o acesso da população escolar indígena aos vestígios materiais de seu passado, bem como o acesso à memória pré-colonial, estavam inaceitavelmente comprometidas e não atendidas em condições aceitáveis.

A partir de então, houve a divulgação sistemática dos avanços da pesquisa arqueológica em Mato Grosso do Sul no meio científico, bem como uma efetiva e regular divulgação de notícias científicas sobre a Arqueologia estadual, pela imprensa local. Porém, a imprensa noticiou também as deficiências funcionais das instalações do LPA, o que fez com que florescesse junto à opinião pública uma consciência pró-ativa no sentido de que deveriam ser adotadas políticas públicas mais eficientes e satisfatórias em prol da preservação do patrimônio cultural sulmato-grossense e dos testemunhos materiais de seu passado. Caracterizou-se assim uma demanda sócio-cultural que denotava inclusive contornos políticos. 
Nos primeiros anos deste século, lastreado por um anseio crescente por parte da população estadual em ter acesso aos documentos arqueológicos explicitadores das características culturais dos processos pretéritos de povoamento humano no estado, isto é, o desejo de conhecer as raízes étnicas e identitárias da geografia humana no atual território sul-mato-grossense, teve início um período de conversações interinstitucionais, envolvendo pesquisadores, o IPHAN e outros órgãos públicos, direcionadas para a criação e posterior implantação de um museu de arqueologia em Mato Grosso do Sul. Assim, no ano de 2003, os esforços descritos anteriormente resultaram na possibilidade de criação de um espaço para sediar o pretendido museu no âmbito do edifício, que então passava por reformas estruturais, do extinto Fórum de Justiça do Estado, o qual, alguns anos depois, passaria a ser a sede do atual Memorial da Cultura de Mato Grosso do Sul "Apolônio de Carvalho". ${ }^{2}$ Perante essa possibilidade, em 22 de julho de 2003, protocolamos no Gabinete da Reitoria da UFMS uma correspondência dirigida ao Magnífico Reitor sugerindo a criação de um museu de arqueologia no âmbito da Universidade.

Como resultado dos entendimentos acima mencionados, por meio da Resolução número 27, de 24 de julho de 2003, o Conselho Universitário da UFMS, então presidido pelo Prof. Manoel Catarino Paes Peró, conforme o contido no processo número 23104.006268/2003-43, criou o MuArq - Museu de Arqueologia da Universidade Federal de Mato Grosso do Sul. Porém, a sua implantação efetiva foi retardada devido a problemas construtivos durante a reforma do prédio do antigo prédio do Fórum.

Durante o período em que as obras ficaram em compasso de espera, ocorreu um evento científico importante que reforçou a convergência de motivos que levaram à implantação do MuArq, ou seja, a realização, em setembro de 2005, em Campo Grande, do XIII Congresso da SAB - Sociedade de Arqueologia Brasileira, considerado um dos maiores congressos de Arqueologia já realizados no Brasil. Esse evento foi coordenado pelo autor deste artigo que, na ocasião, presidia nacionalmente a SAB.

\footnotetext{
${ }^{2}$ O prédio onde, hoje, está instalado o Memorial da Cultura de Mato Grosso do Sul "Apolônio de Carvalho" foi a primeira sede do Governo do Estado de MS. Com a mudança da governadoria e demais secretárias de estado para o Parque dos Poderes, esse local sediou o Fórum Estadual de Justiça. Por sua arquitetura arrojada, quando da época de sua construção, nos anos setenta do século passado, foi tombado como Patrimônio Histórico estadual.
} 
Como as obras de engenharia se deram de forma muito lenta e foram interrompidas por sucessivos períodos, somente em 22 de outubro de 2006, formalmente, foi feita, por parte da então Secretária de Cultura do Governo do Estado de Mato Grosso do Sul, a cedência, em termos de comodato, por prazo indeterminado, do espaço do primeiro andar desse prédio para a instalação do MuArq. As características construtivas que nortearam as obras de engenharia, nesse andar, levaram em consideração o projeto arquitetônico previamente elaborado para a instalação do museu de Arqueologia, o qual foi concebido pelo arquiteto e professor do curso de Arquitetura da UFMS, Ângelo Arruda.

Resolvida a questão básica, foram, enfim, estabelecidas as condições materiais e administrativas que precederam a ação jurídica que viria a constituir de forma concreta e definitiva o MuArq. Em conseqüência, por meio da Resolução número 53, de 27 de setembro de 2006, sob a presidência do Reitor da UFMS, o Prof. Manoel Catarino Paes Peró, o Conselho Universitário (COUN) implantou o MuArq como sendo uma unidade com status de Divisão, vinculado ao Gabinete do Pró-reitor de Pesquisa e Pós-graduação da UFMS. Após esse ato, nova resolução do COUN, a Resolução número 54, de setembro de 2006, fixou as competências do MuArq, caracterizando a unidade criada como:

o órgão responsável pela pesquisa e estudo científico das populações pré-históricas, sociedades, culturas e línguas indígenas do Brasil Central, coletando, recolhendo, salvando, catalogando, preservando, expondo e publicando informações e objetos de valor arqueológico.” A mesma Resolução definiu assim definiu as competências do MuArq:

- coletar e analisar dados arqueológicos na área da pré-história, etnologia e história do Estado de Mato Grosso do Sul, com vistas à reconstituição e compreensão da ocupação regional pelo homem em seus diferentes sistemas culturais;

- cadastrar e providenciar junto ao Instituto do Patrimônio Histórico e Artístico Nacional - IPHAN - o registro dos Sítios Arqueológicos no Estado, como patrimônio da União, bem como colaborar na sua preservação;

- conservar o acervo arqueológico recolhido, com critérios científicos e museológicos, e torná-lo acessível a estudos e pesquisas;

- realizar exposições didáticas de parte do acervo, como instrumento de divulgação, educação científica e preservacionista;

- manter intercâmbio com instituições similares com vistas à divulgação recíproca de informações e atualização científica; 
- constituir banco de dados científicos auxiliar à pesquisa mediante biblioteca especializada, mapoteca, litoteca, coleções de esqueletos animais, coleções etnográficas, etc;

- oferecer apoio a programas de pesquisa e extensão universitária e a cursos de graduação e pós-graduação;

- preservar e assessorar a instituição, quando solicitada, em situações de natureza legal, como "RIMAS”, litígios em áreas indígenas, salvamento arqueológico, preservação de imóveis de valor cultural e/ou históricos, etc;

- adquirir e/ou receber doações de coleções particulares;

- publicar os estudos realizados em periódicos próprios e/ou de outras instituições;

- viabilizar recursos e propor a celebração de convênios relacionados à área de atuação e;

- desenvolver outras atividades dentro de sua área de atuação.

Com a conclusão das obras de engenharia e reformas em geral, no dia 4 de dezembro de 2006, o prédio do Memorial da Cultura foi inaugurado e entregue ao público pelo Governador José Orcírio de Miranda. Em janeiro do ano seguinte, realizou-se a mudança do acervo científico e administrativo e dos equipamentos laboratoriais do LPA para as novas instalações. No espaço laboratorial do "Morenão" permaneceu o setor do LPA dedicado aos estudos de Zooarqueologia, composto por equipamentos científicos e a Coleção Osteológica de Referência. Porém, a mudança para o Memorial da Cultura implicou na necessidade de instalação de uma exposição de longa duração, que, como uma das metas principais do MuArq, tinha por objetivo expor ao público em geral, de forma didática, as evidências dos distintos compartimentos temporais do passado arqueológico de Mato Grosso do Sul.

Com a consultoria museológica da Prof ${ }^{\mathrm{a}}$. Dra. Maria Cristina de Oliveira Bruno, do MAE/USP foi elaborado um projeto de implantação da exposição de longa duração. Esse projeto foi inscrito no Edital do Programa PETROBRÁS CULTURAL, publicado no final do ano de 2006, sendo contemplado com os recursos solicitados (Projeto Cultural PRONAC n. 069778). O projeto museológico que gerou o conceito museográfico específico para tal foi concebido pelo arquiteto e museólogo do Museu de Zoologia da USP, Maurício Cândido da Silva. Durante o ano de 2007 e início de 2008, a equipe técnica-científica do MuArq, sob a coordenação e supervisão dos professores Dr. Gilson Rodolfo Martins e Dra 
Emília Mariko Kashimoto, desenvolveu os trabalhos de execução e montagem previstos no Projeto de Implantação da Exposição de Longa Duração. Concluídas as ações de instalação da referida exposição, a coordenação do MuArq definiu como data para inauguração pública das instalações laboratoriais, administrativas e expositivas, o dia 19 de maio de 2008, data alusiva e inserida na Semana Nacional de Museus, celebração instituída pela Diretoria de Museus do IPHAN, atual IBRAM - Instituto Brasileiro de Museus. A solenidade de inauguração do MuArq (v. fotos no final deste artigo) foi presidida pelo Magnífico Reitor da UFMS, Prof. Manoel Catarino Paes Peró, e contou com a presença de expressivo público composto por professores e alunos da UFMS, pesquisadores de renome nacional, entre eles, o Prof. Dr. Pedro Ignácio Schmitz, ex-presidente e fundador da SAB Sociedade de Arqueologia Brasileira, autoridades universitárias, políticas, civis, religiosas, em cerimônia pública que obteve ampla repercussão na imprensa local e nacional.

Em funcionamento, as atividades de implantação do MuArq foram dinamizadas com o desenvolvimento do projeto intitulado "Implantação do sistema de climatização do Museu de Arqueologia da UFMS", contemplado com recursos do Edital "Mais-Museus", uma iniciativa do IPHAN, que viabilizou a climatização dos seguintes ambientes: recepção da exposição de longa duração, sala da exposição de longa duração, sala de audiovisual (auditório), sala da reserva técnica, sala de reuniões e sala para biblioteca.

Nesse primeiro ano de existência e abertura à visitação pública, o MuArq recebeu um número aproximado de visitantes, em torno de três mil pessoas, na maioria estudantes de ensino fundamental e médio, mas também muitos estudantes universitários, professores e pesquisadores nacionais e estrangeiros, além de turistas de diferentes estados brasileiros e de outros países, cumprindo assim a sua meta estratégica na perspectiva da divulgação do conhecimento científico, da expansão da consciência preservacionista do patrimônio cultural do país e do fomento à novas vocações científicas. Porém, se tivermos que responder uma pergunta sobre qual é a função social primordial do MuArq, a resposta será: COMBATER A IGNORÂNCIA. Somente a propagação horizontal e independente da consciência científica poderá extinguir e barrar o preconceito, a intolerância, o fanatismo e a superstição, abrindo espaço para o florescimento da razão e da liberdade individual de pensamento, expressão e criação. 

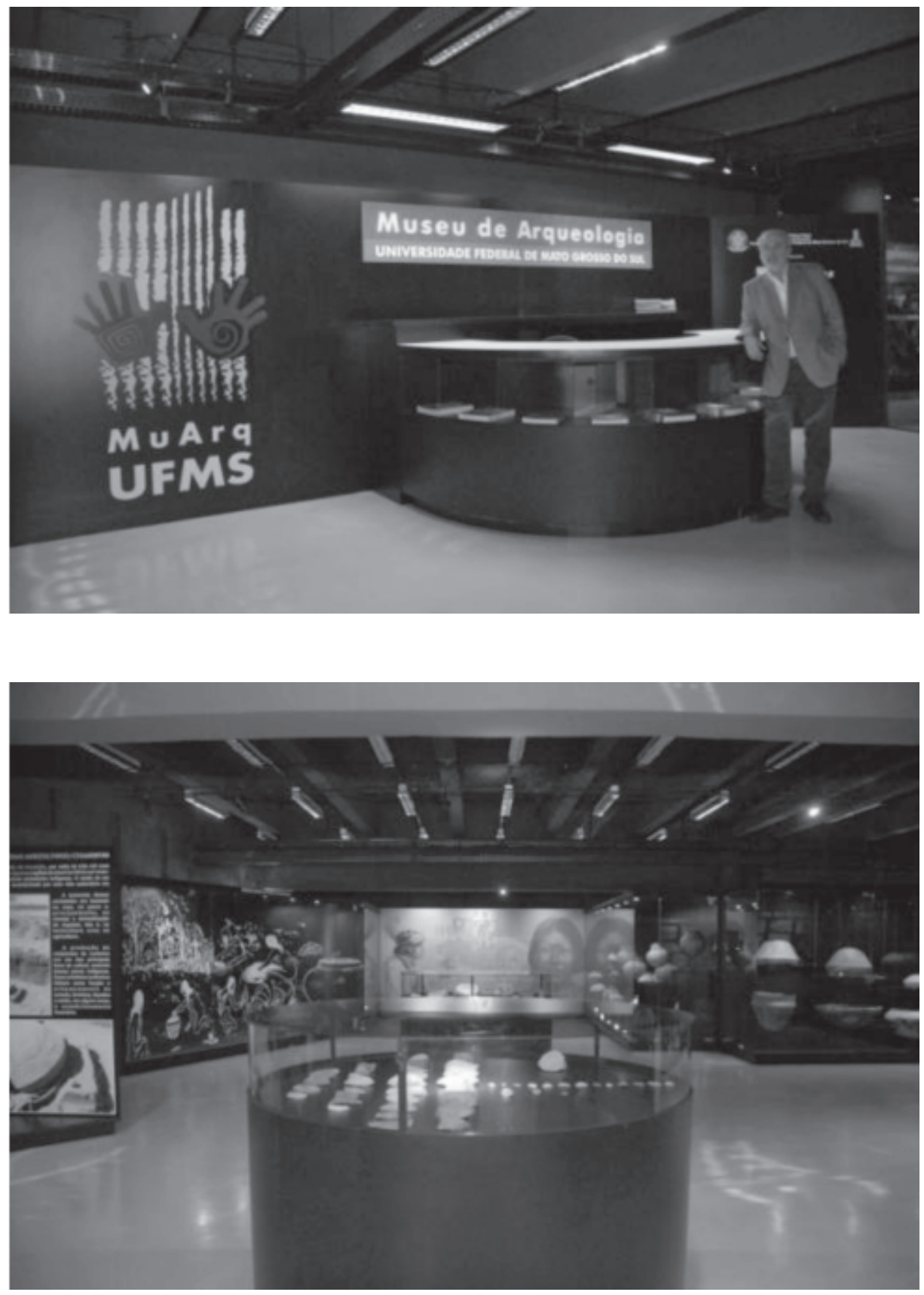

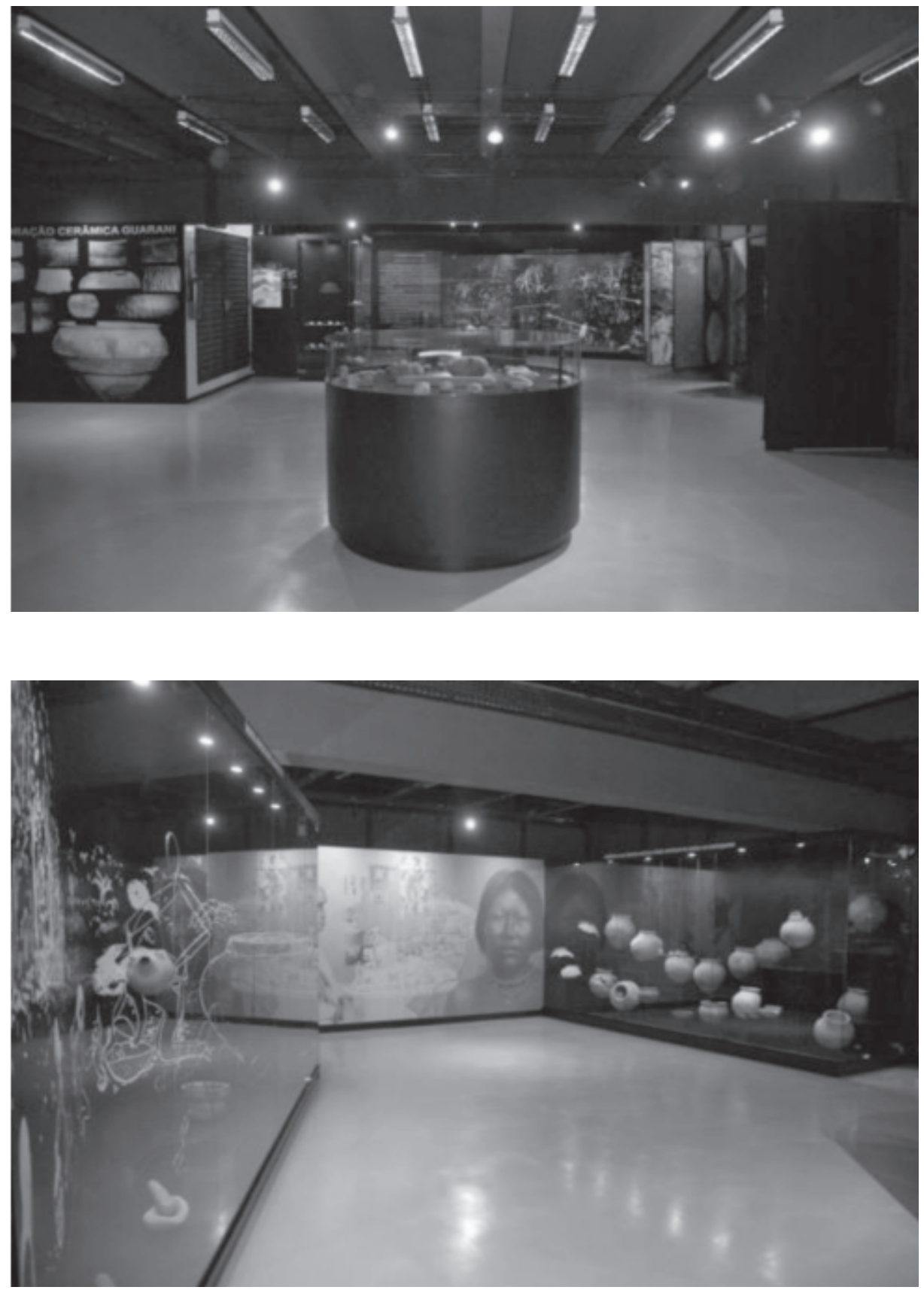

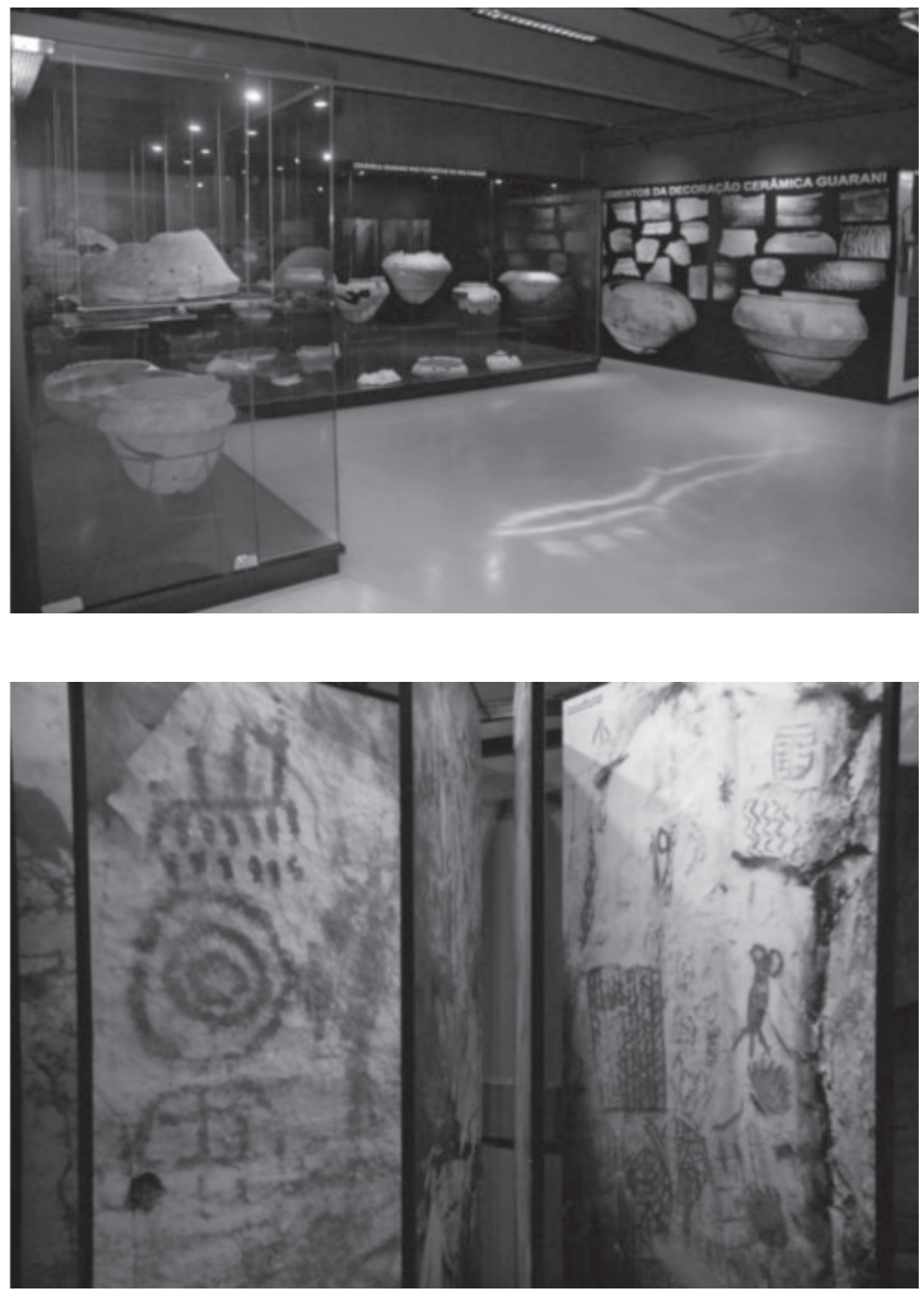

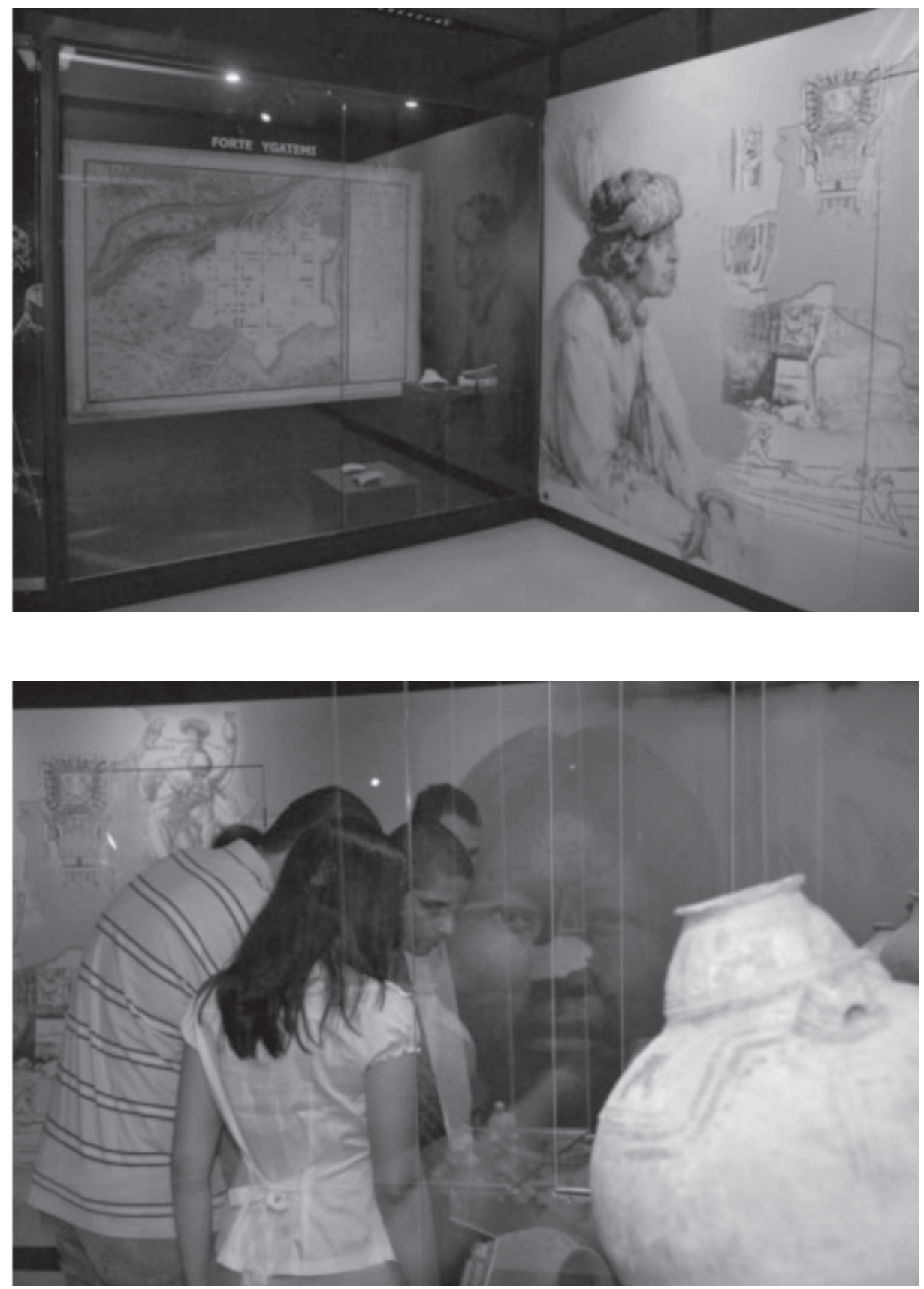

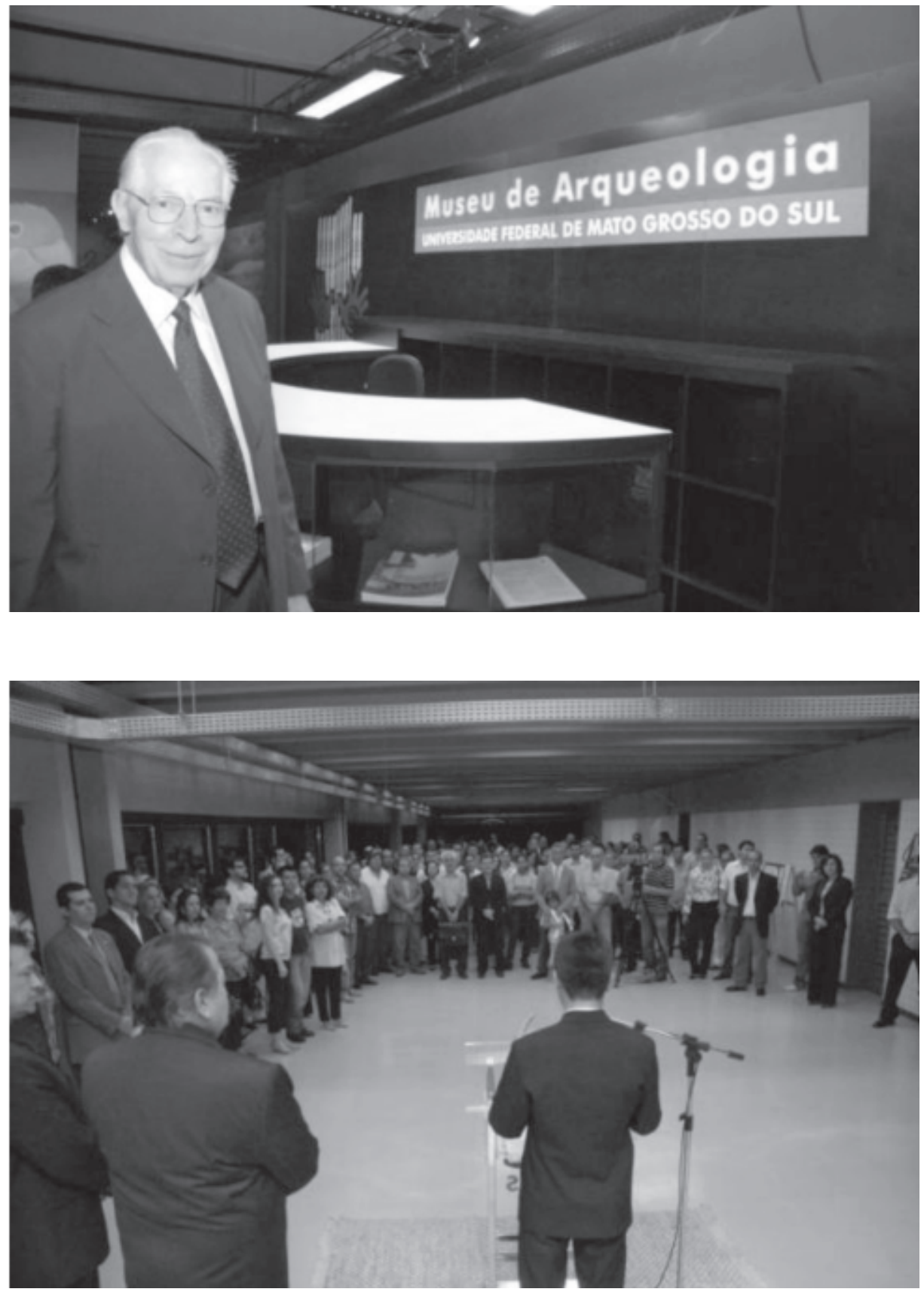